\title{
Génesis del Azul Modernista
}

\section{CONSIDERACIONES HISTÓRICAS}

Entre los críticos que estudian el modernismo hispanoamericano se ha generalizado la tendencia a sobrevalorar el azul y considerarlo el color modernista por antonomasia, siendo relegados a un plano secundario los demás matices de la expresión modernista. Tal error se debe, en gran parte, al juicio hondamente arraigado - y muy difícil de extirpar- de que el $A z u l$ de Darío marca el principio del modernismo, y, por consiguiente, es, como quiere Raúl Silva Castro, ${ }^{1}$ el primer libro modernista de la literatura hispánica. Estas afirmaciones, tanto como la popularidad perenne de $A z u l$, explican la resonancia que el color cerúleo ha ad. quirido como el predilecto y característico del estilo de los modernistas.

En oposición a algunas de las ideas anteriores, deseamos señalar que las investigaciones más recientes de Federico de Onís, Max Henríquez Ureña, Guillermo Díaz-Plaja y Manuel Pedro González ${ }^{2}$ establecen de manera incontrovertible que antes de la publicación de $A z u l$-entre I876 y 1882 - Manuel Gutiérrez Nájera y José Martí ensayaron, con voluntad de estilo, formas literarias pertenecientes a lo que posteriormente

\footnotetext{
1 "El ciclo de lo 'azul' en Rubén Dario," Revista Hispánica Moderna, XXV (1959), 81.

2 Federico de Onís, "La poesía hispanoamericana," Cuadernos (París), 21 (1956), 11-19, y "Martí y el modernismo," en Memoria del Congreso de Escritores Martianos (La Habana, 1953), pp. 431-446; Max Henríquez Ureña, Breve bistoria del modernismo (México: Fondo de Cultura Económica, 1954), y "Martí, iniciador del modernismo," en Memoria del Congreso de Escritores Martianos, pp. 447-465; Guillermo Díaz-Plaja, Modernismo frente a noventa y ocbo (Madrid: Espasa-Calpe, 1951), p. 305; Manuel Pedro González, "José Martí: Jerarca del modernismo," en Miscelánea de estudios dedicados al Doctor Fernando Ortiz por sus discípulos, colegas y amigos (La Habana, 1956), pp. 729-762, y "Conciencia y voluntad de estilo en Marti," en Libro jubilar de Emeterio S. Santovenia en su cincuentenario de escrit. tor, (La Habana, 1957), pp. 191-227.
} 
se denominará la prosa modernista. $Y$, en cuanto a la primera obra en forma de libro de filiación netamente modernista, of recemos el testimonio del crítico argentino, Enrique Anderson Imbert, quien en su brillante ensayo en torno a Amistad fumesta (1885) afirma que "en las letras hispanoamericanas fue Martí el primero en colaborar con el género novela en la renovación literaria que llamamos 'modernismo". 3

En poesía, no es hasta la aparición de la segunda edición de $A z u l$ (Guatemala, x890) cuando Darío se revela como refinado y exquisito creador de versos modernistas. "No es", dice Anderson Imbert, "en el verso, sino en la prosa, donde se decidió a innovar. En este sentido la importancia histórica de $A z u l$, se debe a sus cuentos y prosas poemáticas." 4 Las poesías que integran la siguiente colección de versos rubenianos, Prosas profanas ( 1896 ), afirmaron el triunfo poético de Dario. Pero en este volumen no hay una sola poesía fechada antes de i89r, aunque es posible que algunas hayan sido concebidas antes. ${ }^{5}$ Hacia esa fecha, limitándonos a la poesía exclusivamente, Martí había escrito los tres tomos más importantes de su poética, Ismaelillo, Versos libres y Versos sencillos; Gutiérrez Nájera había producido lo más destacado de su obra; Casal había publicado Hojas al viento y escrito casi todos los poemas de Niave; y Silva llevaba varios años explorando una expresión musical en la poesía. Ante estos hechos, ¡cómo puede la crítica seguir en su empeño de considerar a Darío "el iniciador" del movimiento modernista! Claro se ve que algunos de estos mal llamados precursores habían cultivado formas renovadas pertenecientes a la poética modernista desde I88I, y los demás a partir de r888. Estos son datos imprescindibles para enfocar debidamente la cronología del modernismo, sobre todo si se quiere, como

3 "La prosa poética de José Martí. A propósito de Amistad funesta," en $M e$. moria del Congreso de Escritores Martianos, p. 616. Amistad funesta fue publicada bajo el seudónimo de Adelaida Ral por entregas en el periódico de New York $E l$ Latino-Americano. Se editó en forma de libro pol primera vez en el décimo volu. men de la edición de Obras completas de Martí que hizo Gonzalo de Quesada y Aróstegui (Leipzig: Imprenta de Breitkopf \& Haertel, 1911). Párrafos de corte modernista se pueden encontrar en otro libro que Martí publicó en 1878: Guatemala. Limitándonos al azul, la hipálage de estas líneas demostrará la conciencia artística que permea la obra:

Este que pasa, caballero de una bella dama

azul, es un grave Ministro: la multitud

lo estruja, lo olvida, lo gobierna. (19:69)

4 "Estudio preliminar" en Rubén Darío, Paesía (México: Fondo de Cultura Económica, 1952), p. xiii.

5 Así lo afirma Enrique Anderson Imbert, "Estudio preliminar," p. xv. 
en este ensayo nos proponemos, dilucidar las innovaciones estilísticas de sus momentos iniciales.

\section{Cronología y función de AZUL}

El azul inspiró la definición huguesca "L'art c'est l'azur", prestó la magia de su color al título de la revista parisiense La Revue Bleve, y al de los cuentos de Catulle Mendès Les aiseaux bleus (1888). Mallarmé, encantado por este matiz, hubo de exclamar: "Je suis banté! L'Azur! L'Azur! L'Azur! L'Azur!' Es dudoso que la insistencia con que aparece el azul en los escritos modernistas pueda atribuirse directamente a una de estas fuentes francesas, mas es innegable que entre los iniciadores del modernismo José Martí, antes que ningún otro, descubrió las seducciones estéticas del azul, e incorporó este color a su léxico como constante estilística. El azul, sin embargo, sólo representa uno de tantos rasgos expresivos de estirpe genuinamente modernista presentes en su obra entre I875 y r885 -fenómeno que refuerza la aseveración de los arriba men. cionados críticos (la cual subscribimos ${ }^{6}$ ) de que a Martí, tanto como a Nájera, Silva y Casal, hay que clasificarlo como iniciador y no como pre. cursor del modernismo.

El ya aludido ensayo del distinguido crítico chileno, perito en la obra primigenia de Rubén, rastrea el azul en los escritos del bardo nicaragüense, y analiza este color en su doble vertiente de valor anímico y estilístico. Quisiéramos complementar dicho trabajo con un análisis sistemático y cronológico de la función y sentido del azul en la obra de Martí que, según Juan Ramón Jiménez, "vive (prosa y verso)"7 en el arte de Rubén. No pretendemos perpetuar la inexacta concepción de que el azul es el color más trascedente del modernismo; para nosotros sólo representa uno entre varios colores relevantes de que se sirvieron los modernistas en la creación de su estilo. Martí principió a utilizar el azul simbólicamente a partir de 1875 , y este hecho confirma la necesidad de concederle la prio. ridad de haber iniciado - al menos en prosa-formas modernistas que enriquecieron los procedimientos estilísticos de las letras hispánicas.

El año I 875 marca la primera llegada del exilado Martí a México; el azul en este año reviste las siguientes manifestaciones: "Está muy lejos

- V. nuestro estudio "Los supuestos 'precursores' del modernismo hispanoamericano," Nueva Revista de Filología Hispánica, XII (1958), 61-64.

7 Españoles de tres mundos (Buenos Aires: Losada, 1942), p. 33. 
el azul soñado"; ". ". ama [Pedro Castera] lo azul, porque lo azul da idea poética del exquisito espíritu por quien siente amor tan alto..." (50:24) Y del proverbio teatral Amor con amor se paga, estrenado en la capital mexicana el mismo año, entresacamos las líneas siguientes:

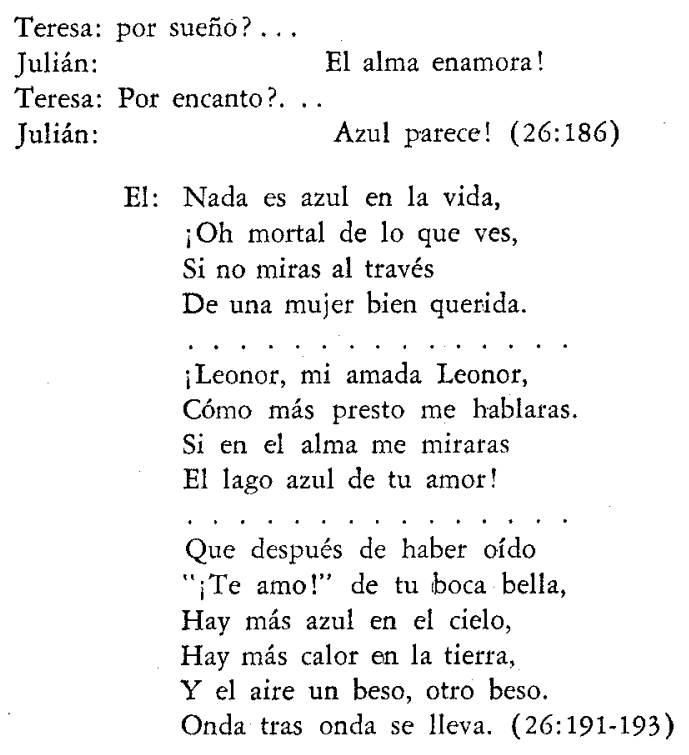

Estas citas contienen los textos que inician el ciclo azul de la obra martiana, y en ellos está patente ya el sentido genérico que este tropo tendrá en las producciones maduras del artista; sugerirá idealismo, belleza, alegría, perfección moral o espiritual, y el deseo de evadirse de la realidad y encontrar solaz en una región empírea. Estas, precisamente, son las cualidades que don Juan Valera percibió en el azul de Dario, aunque el crítico español puso en tela de jucio el valor de encarnarlas en el azul:

¿Por qué, en este caso, lo azul (aunque en francés no sea bleu, sino azur, que es más poético) ha de ser cifra, símbolo y superior predicamento que abarque lo ideal, lo etéreo, lo infinito, la serenidad del cielo sin nubes, la luz difusa, la amplitud vaga y sin límites, donde nacen, viven, brillan y se mueven los astros?

8 Obras completas (La Habana: Trópico, 1936-1953), XLII, 98. De aquí en adelante daremos el volumen y la página de esta edición en números arábigos dentro del texto.

9 Cartas americanas (Madrid: Imprenta Alemana, 1915), pp. 267-268. 
¿En qué consiste el fenómeno estilístico que Valera denomina "cifra, símbolo y superior predicamento"? Raúl Silva Castro capta lo esencial de este problema técnico cuando asienta la necesidad de diferenciar entre el uso de azul en calidad de sustantivo y de adjetivo:

En el primer caso [el del sustantivo]... azul es una comarca espiritual, intima, que posee o señorea el artista por el mero hecho de serlo... cuando se emplea la voz azul como adjetivo, la connotación cambia según la pala. bra a la cual va a calificar . . 10

Aunque abundan los casos de símbolos cromáticos de valor sustantivado -tanto en Darío como en Martí11 - lo más común es que sean de naturaleza adjetiva. Según nuestro entender, el epíteto cromático adquiere categoría de símbolo cuando su función de calificador de un sustantivo dado implica más que el sentido literal, es decir, cuando evoca una realidad imaginada que rebasa los límites de la física. El símbolo cromático formado así tendrá un doble plano de significación. Tomemos como ilustración una cita de Dario: "Sí, dentro de la jaula de mi cerebro está preso un pájaro azul que quiere su libertad..."12 Este pájaro azul, clato está, induce al lector a imaginar mucho más que un ave de tal color; de ahí la doble faceta de la imagen. Al símbolo cromático de este tipo aplicamos la terminología de Carlos Bousoño y lo llamamos símbolo bisémico. En cambio, cuando la relación de adjetivo y sustantivo es sinestésica, es decir, cuando el adjetivo cromático y el sustantivo yuxtapuestos no integran una relación lógica (e.g. pensamiento azul), entonces la catacresis que resulta encarna un símbolo cromático potencial. Para constituirse en símbolo auténtico se necesita que la unión catacréstica de sustantivo y adjetivo tenga valor estético o decorativo $\mathrm{y}$, a la vez, un estrato noético-emotivo.

Volviendo al tema, el primer rastro de azul que Silva Castro descupre en la obra rubeniana data de 1884 , nueve años posterior a los ejemplos ya citados de la obra martiana. En esta manifestación inicial se trata

10 Op. cit., p. 95.

1n V. como ejemplo de este procedimiento, el siguiente recado de Martí a Manuel A. Mercado:

Aquí va la correspondencia de esta semana, en que he puesto su poco de color, por lo que de nuevo me recomiendo a la bondad del caballero que repasa las pruebas, no vayan a salir borrones los que yo he procurado, repartir de modo que donde se debe haya azul, y donde cabe, amarillo. (69:59) (El subrayado es mío.)

12 Cuentos completos (México: Fondo de Cultura Económica, 1950), p. 22. 
de una conjugación implícita de cielo y azul, imagen que vio la luz en un texto desconocido hasta que Diego Manuel Sequeira lo publicó en su libro Rubén Dario, criollo (1945):

A las veces se torna rudo y grave, y entonces pulsa el arpa resonante sobre una cumbre; la melena alzada, con el rostro hacia el sol: le dan de lleno los rayos en la frente; los espítitus que vuelan agitando las tormentas en el azul, se acercan, le rodean ...13

La palabra azul del sintagma agitando las tormentas en el azul carece de la categoría simbólica que esta voz adquirirá en el período I886-x889 que Silva Castro denomina el del ciclo de lo azul en Darío.

En la obra de Martí, el azul tiene semejante forma embrionaria, r.e., la aproximación de cielo y azul, éste, sin embargo, con valor adjetival. En una poesía sentimental, titulada "Sin amores" leemos (I875):

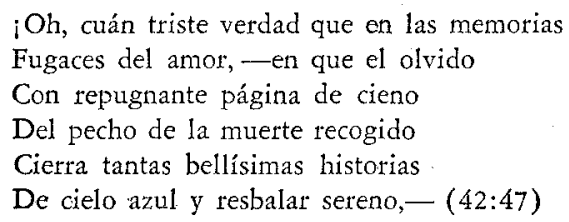

Pero en ese mismo año el azul comienza a cobrar mayor significación subjetiva, como se notará en la cita siguiente, donde se presagia el uso simbólico del tropo denotador de lo excelso, lo etéreo, lo imaginativo:

Sin discusión alguna, en Madrid se vive estrecha vida científica, y abundante y buena vida literaria. Son en esto, sin duda, parte principal, las condiciones imaginativas y el cielo todavía azul de los españoles, no muy asimilables ciertamente a las graves especulaciones alemanas en que, a despecho de la originalidad, mas con trabajo y ampliación notables, ocupó su inteligencia Sanz del Río, y la ocupan hoy Patricio Azcárate, Mesía, Francisco Giner y el lógico, el honrado, el vigoroso Salmerón. (47:95)

Cuando por segunda vez el vate nicaragüense utiliza la voz azul, ésta revela atributos totalmente modernistas; se trata del pájaro azul-símbolo bisémico del cuento con idéntico título (r886) - que denota "una región empírea hacia la cual tienden los anhelos de los artistas".14 Idéntica ima-

1\% Citado por Raúl Silva Castro, op, cit., p. 92.

14 Silva Castro, op, cit., p. 83. 
gen que, por cierto, recuerda L'oiseau bleu (1908) de Maeterlinck y Les oiseaux bleus ( 1888 ) de Mendès, fue utilizada por Martí un año antes en su novela Amistad funesta:

Estaban las tres amigas en aquella pura edad en que los caracteres todavía no se definen: jay! en esos mercados es donde suelen los jóvenes generosos, que van en busca de pájaros azules, atar su vida a lindos vasos de carne que a poco tiempo, a los primercs calores fuertes de la vida enseñan la zorra astuta, la culebra venenosa, el gato frío e impasible que les mora en el al$\mathrm{ma} !(25: 18)$

Los pájaros azules martianos son de índole tan idéalista como el pájaro azul rubeniano; tienden su vuelo a una región igualmente elevada, pero, a diferencia del de Darío, no evocan las ansias de libre creación artística, sino la ilusión, alegría y perfección espiritual que anhela la juventud.

Al año siguiente - I887- se da la segunda de las dos variantes del símbolo cromático adjetival en la obra de Dario, el símbolo que está montado sobre una base catacréstica-cuento azul: ". . la historia de Berta, la niña de los ojos color de aceituna, fresca como una rama de durazno en flor, luminosa como un alba, gentil como la princesa de un cuento azul" (El palacio del sol).15

Este símbolo cromático de filiación sinestésica, tan característico del estilo modernista, ${ }^{\mathbf{1 6}}$ aparece en la obra martiana en $187^{6}$-una década antes de su primera manifestación rubeniana. Se encuentra en un pasaje donde Marti identifica la música con la creación literaria - principio éste que proviene del venero verlainiano de la estética simbolista:

Pero hay entidades poéticas cantorés de lo venidero, arúspices divinos de una religión vasta y azul. Si no supiera yo que andan intencionalmente, diría que estos poetas andan equivocadamente por la tierra. Si los espíritus tu. viesen forma, se diría que unos tienen forma de terruño; éstos dè nube. Viven entre claridades opacas, realzan lo que tocan, embellecen lo que miran, purifican donde hablan... Es un lenguaje rumoroso, una cadencia tenue; algo de amanecer y de gorjear lejano de aves. (50:170-171)

De 1876 en adelante empiezan a abundar los símbolos cromáticos de

15 Cuentos completos, p. 35.

Ii6 Carmelo Bonet en La técnica literaria y sus problemas (Buenos Aires: Nova, 1957), p. 59, of rece ejemplos de relaciones sinestésicas en los autores del Siglo de Oro español: canoro sueño, verdes halagos (Góngora); blanca aurora, verde edad (Lope). 
naturaleza sinestésica en la obra de Martí. En 1877 , viajando con destino a Guatemala, describe sus impresiones de Curaçao, y utiliza la imagen dias azules:

El aire es cálido: La atmósfera transparente, desnuda a los ojos curiosos el aseado ajuar exterior de las pesadas casas, que con sus árboles menguados, y sus tejados rojos y sus paredes altas, agujereadas por ventanas menudisimas... recuerdo a la memoria, que se goza generosamente en volvernog a nuestros inmaculados días azules; esos juguetillos de madera que labran y pintan en sus horas de ocio los labriegos de la opaca Alemania. (55:159)

Y, del mismo año es el recado alicaído a Manuel A. Mercado: ". . no ha habido en todo el mes un solo día azul" (69:62).

En 1878 , dos tropos de significación antitética -año negro y años azules-indican la tristeza y la alegría de años sucesivos:

Con esto; con mi propósito de pagar aquí, esclavo de mis deudas un año, e irme; y con que Carmen cante a mi lado tan gozosamente como ahora canta, paso este año negro y espero otros años azules. ¡Quién sabe si el permanente azul no es de la tierra! (68:60)

Es un hecho de sumo interés y de gran trascendencia para trazar el empleo del azul simbólico entre los modernistas - que Darío se sirve del mismo tropo diez años más tarde, al comentar el estado de ánimo de la gente que se prepara a poner fin a la temporada veraniega chilena:

Las familias santiaguinas que han venido a Valparaíso y Viña del Mar van de vuelta. Se van a sus hogares de siempre, mas es de dudarse que no lleven - digo, las almas jóvenes y soñadoras-la esperanza del año que vie. ne. El año que viene es siempre azul. Se ve un arco iris en todo porvenir de mujer, una libélula fugaz y cristalina, un vago sueño, y las damas son las que tienen más derecho de llevar, si no esperanzas, al menos recuerdos. ${ }^{17}$

En un cuento del mismo año, Darío une los colores simbólicos negro y $a z \mathfrak{z}$-como Martí en el texto de 1878 . Se trata de la muerte repentina de una muchacha y el trágico desenlace subsiguiente de un idilio. El contenido anímico de negro y azul recuerdan el párrafo de Martí. En El Heraldo de Valparaíso del 17 de marzo de 1888 escribió Darío:

$\rightarrow$ Oh! Ese joven es hoy un escéptico y un corazón de hielo. El año que vino fue para él negro.

17 Obras desconocidas de Rubén Dario, ed. Raúl Silva Castro (Santiago: Prensas de la Universidad de Chile, 1934), p. 129. 
-_iSí, pero para ella siempre fue azul! Voló a ser rosa celeste, alma sagrada, donde debe de existir el ensueño como realidad, la poesía como lenguaje y como luz del amor!

En ambos modernistas el estado eufórico producido por el amor evoca la voz azul, y el negro concretiza los sentimientos de desilusión, tragedia y fracaso.

En la obra de Martí y Darío hay otro caso de coincidencia en el uso de azul. El tres de febrero de I888, en La Epoca de Santiago, vio la luz el cuento rubeniano titulado "Carta del país azul" que lleva por subtítulo "Paisajes de un cerebro." El valor del azul simbólico del título lo sugiere el cuentista al comienzo de su narración:

Ayer vagué por el país azul. Canté a una niña; visité a un artista; oré, oré, como un creyente en un templo, yo el escéptico: y yo, yo mismo, he visto a un ángel rosado que desde su altar lleno de oro, me saludaban con las alas. Por último, juna aventura! $!^{19}$

El paisaje interior que Dario caracteriza, sirviéndose del etéreo azul, es el del amor, de la emoción religiosa y de la experiencia estética; el poeta en su su vagar por aquel país célico, lo contempla todo a través de un cristal azul - cáliz azul y mirada azul son otras dos imágenes de este relato-y escribe una 'carta' "impregnada de aroma de ilusión".20

La variante martiana aparece en el plural en un pasaje de Amistad funesta ( 1885 ):

Todo en la tierra, en estos tiempos negros, tiende a rebajar el alma, todo. libros y cuadros, negocios y afectos, aún en nuestros países azules. (25: $37-38$ )

En esta crítica del materialismo de su época, Martí yuxtapone otra vez el azul y el negro, simbolizando las cualidades espirituales y nobles de "nues. tra América" con el adjetivo azul.21

18 Cuentos completos, p. 78.

I9 Ibid., p. 65 .

20 Ibid., p. 69.

21 Manuel Pedro González ha comentado esta coincidencia tropológica: "Me inclino a creer que Darío leyó amorosamente Amistad funesta y que de estos paises azules martianos desciende en línea recta el título del relato "Carta del país azul"... ["José Martí: Jerarca del modernismo," en Míscelánea... Fernando Ortiz, p. 742, n. 22.] 
En otras formaciones simbólicas de azul -todas escritas antes de la publicación de $A z u l \ldots$ - encontramos en la obra martiana conjugaciones inusitadas de filiación simbolista como las siguientes: sueñecillos azules (I88I), tristeza azul (1882), azul el mar y el alma, (I883), rosas azules ( 1885 ), los ojos de un azul claro y los pensamientos (I886) ${ }^{22}$ :

$\mathrm{Y}$ de noche, entre los rizos rubios de los niños, revuelan sobre la cándida almohada, sueñecillos azules. (28:47)

Emerge de sus versos [los de Longfellow] una hermosa tristeza, la tristeza azul de aquel que no ha sufrido, no la tristeza mordedora, inquieta y bár. bara de los infortunados. (17:216)

[En junio es] azul el mar y el alma. (29:168)

...Lucia que cuando veía entrar a Juan sentía resonar en su pecho unas como arpas que tuviesen alas, y abriise en el aire, grandes como soles, unas rosas azules, tibeteadas de negro ... (25:30)

Tiene los ojos de un azul claro [la esposa del Presidente Cleveland], y los pensamientos. (33:185)

Una variante de azul -celeste- aparece en la época primigenia del cromatismo martiano, en 1876 :

...tal podría decirse que todos los poetas españoles habían besado a las mujeres en la boca, y que fue Ruiz de Alarcón el primero que supo que podía besátseles la frente. Así impregnada de casta tenuidad, es la mujer celeste de Alarcón. (50:162)

El valor genérico del plano real de este matiz simbólico es pureza e idealismo, como se verá en la configuración de 1877 que a continuación ofrecemos:

Un espiritu celeste, el de mi amorosa criatura, me ha dado brío secreto para quebrantar en bien de todas éstas, para nadie útiles, ligaduras: ¿qué habtá erróneo que nazca en su espíritu altísimo y perfecto? (68:19)

La mayoría de los textos martianos aducidos hasta ahora, se definen por el uso catacréstico del símbolo cromático. Igualmente frecuente es la técnica bisémica que presta una dimensión simbólica al lenguaje discursivo.

22 Otros ejemplos antes del 88 se darán más adelante en el apartado sobre la significación de azul. 
La bisemántica permite una descripción objetiva, que a la vez, abarca actitudes e impresiones subjetivas del poeta, expresadas éstas en el plano figurado de la imagen. Tal, precisamente, es el procedimiento de las líneas siguientes ( 1888 ) :

Y el reverendo, vestido de negro, que lee en aquel instante su estudio lau. reado sobre la "mente automática" en un diminuto cuaderno de cubierta azul, que por lo que dice y por la manera de decirlo es digno de más aplausos y público. (36:77)

El detalle del cuaderno azul, usado por un reverendo que pronuncia un discurso ante un congreso antropológico, podría pasar inadvertido por el lector no avisado. En la obra de Martí el procedimiento bisémico, a veces muy sutil, indica su estado de ánimo frente a la realidad circundante. En el texto citado hay una implícita aprobación de la opinión general, del todo favorable, respecto al reverendo.

En la siguiente construcción bisémica, el poeta se sirve del vocablo precisamente para insuflar valor espiritual en el adjetivo azul (1886):

Se ve que muchos niños han nacido en la noche, y que, bajo una tienda azul precisamente, vinieron de una misma madre dos gemelos. (33:86)

Martí admiró tanto el "esprit de corps" de los habitantes de Charleston, Carolina del Sur, ciudad destruida por un terremoto, que al describir el acontecimiento en una crónica de prosa épica, hizo del azul vehículo de nobles e ideales dimensiones.

La hipálage, figura que atribuye a un sustantivo el adjetivo que corresponde a otro nombre del mismo texto, también de origen a formas simbólicas de color azul. En I888, Martí describe el heroísmo de algunos marineros incapacitados y jubilados; a través de un desplazamiento implícito del color del océano, el azul cobra significación moral:

A la otra banda de Nueva York, en Staten Island, hay una casa de inválidos - "Snug Sailor's Harbor"- donde no van más que las víctimas de la guetra de mar... No es necesario mucha poesía para sonreír con ternura cuando pasan aquellos viejos, callados y azules! (36:156)

Similar proceso de simbolización cromática se observa en el párrafo que of recemos a continuación, donde en la imaginación del artista el color del cielo se difunde y tiñe toda la atmósfera. Martí está presenciando el desfile 
de trabajadores en una fiesta nacional y la imagen aire azul da idea de su alma conmovida ( 1887 ):

Y no se ha escogido el día cuando el frío hostil cierra las almas, como cierra la noche las flores sensibles; no cuando el cielo está negro ceñudo; no cuando caen las hojas; sino cuando, como en símbolo de la humanidad orea. $\mathrm{da}$, lo viste todo de fiesta natural el aire azul de Septiembre ... (35:10)

A diferencia de la evolución del azul en la obra de Darío, quien parece esquivar esta voz cromática durante los años posteriores a $1890^{23}$, en Martí este tropo retiene su vigor anímico, noético y estético hasta la muer. te del poeta. En r 890 , un lustro antes de su inmolación en Dos Ríos, escribió:

Los bávaros ${ }^{24}$ han estado de gran fiesta, para que se vea que no olvidan a Bavaria, ni a su romántico rey Luis, que por rey murió y vive por poeta, e iba en uno de los cuadros, sentado tristemente, a la sombra de una roca azul, en un bote de oro. (39:96)

En 1893 :

La hermana poetisa, que vive de enseñar, habla enamorada de nuestros tra. bajos y de nuestro valer, de la emigración honrosa de Cuba, del rincón azul donde se cría el genio. $(10: 207)$

En $1894: 25$

No se enoje ni se encele [Gualterio Garcia]. Ya estoy bueno. Fue, dígale a Rosalía, a Alí, a Fefa, el corazón azul. (67:42)

$Y$, finalmente, en un diario que contiene apuntes escritos al vuelo unos días antes de morir ( 1895 ):

Al fando de la casa, la vertiente con sus sitieríos cargados de $\operatorname{cocos}$ y plá-

23 Silva Castro, "El ciclo de 10 "azul en Rubén Dario," p. 90: ". . las menciones a lo azul son menos frecuentes, más espaciadas, después de $1890, \mathrm{y}$, según nos parece advertir, faltan ya a las alturas de 1893 en los cuentos y en una fecha tal vez más avanzada, en las poesías..." A continuación Silva Castro reproduce citas correspondientes a los años 1890,1892, 1893, 1895, 1896, 1904 en que figura el azul como elemento artístico.

24 Hemos tomado la libertad de reemplazar la palabra bárbaros que aparece en el texto original de la Edición Trópico por bávaros.

$25 \mathrm{~V}$. más adelante la cita de la poesía escrita el mismo año y dedicada a la hijita de Manuel Gutiérrez Nájeta. 
tanos, de algodón y tabaco silvestre: al fondo, por el río, el cuajo de potreros; y por los claros, naranjos, alrededor los montes, redondos, apacibles: y el infinito azul arriba con esas nubes blancas, y surcan perdidas ... detrás la noche. - Libertad en lo azul.- (56:105-106)

\section{SIGNIFICACIÓN DE AZUL}

El azul martiano pertenece al léxico modernista en el sentido de que comparte el tenor idealista que caracteriza su manifestación en la obra de otros modernistas. Pero nunca reviste valores convencionales, nunca es un tropo carente de un sentido anímico profundo y subjetivo. La doble dimensión de la vida martiana - la heroica y la artística- presta matices originales a éste, igual que a todos sus símbolos y metáforas. Es que en la dilucidación de cualquier elemento estilístico de Martí hay que tener en cuenta que fue uno de aquellos excelsos espítitus cuya alma Edith Hamilton pintó con las siguientes frases nobles:

They suffer for mankind, and what preoccupies them is the problem of pain. They are peculiarly sensitized to the "giant agony of the world." The world to them is made up of individuals, each with a terrible power to suffer, and the poignant pity of their own hearts precludes, them from any philosophy in the face of this awful sum of pain and any capacity to detach themselves from it. They behold, first and foremost, that most sorrowful thing on earth, injustice, and they are driven by it to a passion of revolt... And yet they never dispair. They are rebel fighters. They will never accept defeat. It is this fact that gives them their profound influence, the fact that they who see so deep into wrong and misery and feel them so intolerable, never conclude the defeat of the mind of man:26

De ahí que en la ontología martiana el azul se vincule con un mundo espiritual que alcanzan los que se han sacrificado en el servicio de la humanidad ( 1883 ) :

Hay criaturas que se salen de sí, y rebosan de amor, y necesitan darse, y traen a la tierta una espada invisible, siempre alta en la mano, que enciende con su fulgor los campos de batalla, mientras viven, y cuando caen en tierra cubiertos de toda su armadura, vuela cual llama azul, al sol. (29:45)

Sólo el visionario, el hombre superior, llega a ver las capas superiores del mundo ideal martiano, morada de filiación platónica (I883):

26 The Greek Way to Western Civilization (Nueva York: New American Library, 1959), p. 199. 
Es dado a ciertos espíritus ver lo que no todos ven; y allí se vieron como juramentos al Cielo azul por espadas de oro; y lágrimas con alas. (18:91-92)

La espada invisible y la armadura de la penúltima cita simbolizan la lucha humana, la misma que en el último texto se expresa por medio de espadas de oro y dos otros tropos idealistas, cielo azul y lágrimas con alas.

El azul también es el vehículo expresivo de los sueños, las aspiraciones y las utopías que Martí elaboraba como formas de evasión (1892):

Pero de ese argumento del interés se ha de tomar nota, por lo que tiene de humano, y de fuerte por tanto, y por lo que hay en él de justo. Pero no se ha de responder a él, con la arrogancia de la profecía que ofrece, por la potencia del deseo, democracias milagrosas y repúblicas de madreperlas, con celajes de azul y oro... (3:190)

En éste, como en otros textos, el azul está unido al oro, intensificando así la nota idealista por medio de dos componentes cromáticos de significado parecido.

La alegría que proporciona la perfección humana está involucrada en el siguiente empleo de azul (I882):

¿Viste en la mat la nave rota por la tremenda furia de los vientos? Así es, así destruye el alma el borrascoso amor del adulterio. $\mathrm{Y}$ viste luego cuando en el hogar todo es azul, cuando la confianza tesplandece, cómo semeja el corazón huerto florido, lleno de frutas sazonadas y de flores con perlas de rocío? (26:166-167)

Grossman está hablando con Fleishch en este pasaje de la segunda versión del drama moral Aduiltera, rehecho, según Willis Knapp Jones, en I882. ${ }^{27}$ Este diálogo en que Grossman evoca un cuadro de felicidad doméstica (azul, bucrio florido, frutas sazonadas, flores con perlas de rocio) falta por completo de la primera versión escrita en 1872. El hecho de que únicamente en la refundición aparezca la voz azul, es de suma trascendencia para trazar la cronologia de azul en la obra de Martí.

La felicidad de un estado eufórico suscita la siguiente voz azul usada en una carta a Enrique Estrázulas, de visita en París (I888):

Desde que llegamos a los boulevares, y nos cortamos la barba en pico, no

27 "José Martí, dramaturgo", en Memoria del Congreso de Escritores Mariianos, p. 721 . 
hà habido memoria, ni elocuencia, ni pintura, más que para las señoritas. Ahora sí que me van a venir buenas cartas de allá, humeantes como la sangre y empapadas de azul! (65:182)

El azul denota asimismo excelencia espiritual y superioridad moral:

Sé de un hogar, esmaltadö

De tres nelumbios azules

Que sobre la alfombra vuelan

Vaporosos como nubes.

Tengo yo un ángel amigo

Del orden de los querubes

Que al hogar de sus hermanos,

Catiñoso me conduce

$\mathrm{Y}$ entre las almas gemelas

Del ángel de alas de nube,

No vi yo tres más hermosas

Que estas tres flores azules. (73:107-108)

El artista modernista, el esteta, se revela notablemente en el tropo catacréstico música azul (1894) que aparece en un poema dedicado a la hijita de Manuel Gutiérrez Nảjera:

En la cuna sin par nació la airosa

Niña de honda mirada y paso leve,

Que el padre le tejió de milagrosa

Música azul y clavellín de nieve. (42:195)

El azul simbólico de Martí no es tan poliédrico como el oro; carece de las ramificaciones estéticas de éste en el sentido de que raramente se usa como representación de la perfección literaria, de la excelencia estilística. ${ }^{28}$ Pero en aquellas ocasiones cuando sí reviste tal tenor, se aproxima en valor noético al oro:

He [Antonio Fernández Grilo] sings of everything that weeps-a child without a mother, a house without a head-a woman without love, a tree

28 De los muchos ejemplos que podríamos aducir, bastarán estos dos textos:

¿Qué entendimiento de coloso! ¡qué pluma de oro y seda y iqué alma de paloma! (18:42)

... y en párrafos que resplandecían como círculos de oro recoge esos deseos de amor y trabajo, y anuncia a la república unida que el sur ha muerto, y ha nacido otro. ( $33: 216)$ 
without leaves, a land without glory. If verses could have colors, his would be blue and rose colored. $(51: 23)$

Esta atrevida correspondencia de versos y colores formó parte de un artículo publicado en 1880 en el Sun de Nueva York. El azul y el rosa evocan cualidades de ternura y sensibilidad literaria en este ensayo, uno de los primeros textos significativos de la cromología martiana. Con él rematamos el análisis cronológico y estilístico del azul martiano.

Esta voz cromática representa uno de los relevantes recursos estilisticos inspirados por el Parnaso, el Simbolismo y el Impresionismo-movimientos europeos coevales que fueron asimilados por José Martí y Manuel Gutiérrez Nájera entre I875 y I882, los años decisivos en la meta. morfosis de la renovación artística que denominamos modernismo. Martí utiliza la voz azul a partir de 1875 ; Nájera desde $1876 ;^{29}$ y Darío por primera vez en i884. Tal estudio comparativo señala, una vez más, la imprescindible necesidad de rectificar el esquema cronológico que todavía mantiene la crítica tradicionalista, la cual sigue fijando el comienzo del modernismo en I888, y, a la vez, considera a Manuel Gutiérrez Nájera, José Martí, José Asunción Silva y Julián del Casal como precursores del movimiento. No nos guía un deseo de desvalorar la obra de Dario dentro del modernismo, ni de discutir su altísimo valor artístico en las letras hispánicas. Cada uno es grande y noble en sí, como dijo el mismo Rubén. Reconózcase entonces la labor trascendental de los iniciadores del modernismo y emúlese la franqueza de Juan Ramón Jiménez quien, al considerar la influencia de Martí -amén de la de Díaz Mirón y Casalsobre Darío, afirmó:

Pero en él estaba Martí. Este, con los Versos sencillos, influyó en Dario. Recuerde el poema de aquél donde habla de "la bailarina española". Muchos poemas de Martí se condensan y quedan reducidos en Dario a una línea. Martí le llamaba su hijo y quería que fuese su sucesor. Le sucedió como cronista en La Nación, de Buenos Aires, y el artículo que allí escribió Rubén en ocasión de la muerte de Castelar parece de Martí. De éste le vino, también, el amor por los clásicos españoles y los giros estilísticos en los poemas de tipo menor:

La niña de Guatemala, la que se murió de amor.

29 La primera manifestación de azul con valor simbólico en Nájera se da en el poema "Luz y sombra" 1876: "Es blanca tu conciencia y azul tu pensamiento." V. mi estudio "Función y sentido del color en la poesía de Manuel Gutiérrez Nájera," Revista Hispánica Moderna, XXIII (1957), 1-13. 
Darío tiene un poema dedicado a Bonafoux que parece de Martí, por sus galas y sus gracias. Hay un cierto Darío que no se comprende sin Martí. La bailarina española de Rilke, a su vez, recuerda La gitanilla de Dario. El soneto a Carolina, de éste, es Martí puro. También Díaz Mirón influyó sobre Darío. Y Julián del Casal, en $A z u l .^{30}$

\section{TEORÍA LITERARIA}

Además de lo indicado hasta ahora respecto a la cuestión del color en la obra de Martí, hay que tener en cuenta que acompaña su cromología simbólica un cuerpo nutrido de ideas teóricas que revelan la conciencia que tenía de la revolución artística que realizaba en el período que va de I875 hasta la publicación de $A z u l$. . . Desgraciadamente, la naturaleza de este estudio no permite el análisis de la multifacética doctrina literaria de Martí; tendremos que limitarnos a explorar en detalle sólo aquellos pronunciamientos vinculados con el tema del color. Pero éstos, tanto como la precedente elucidación del desarrollo de azul, bastarán para indicar que hoy en día resulta imposible aceptar la autenticidad histórica de las afirmaciones de Rubén de que él inició el movimiento modernista. ${ }^{31}$

En I875 Martí asentó los siguientes conceptos que en su época no debieron ser considerados menos que revolucionarios:

El color tiene más cambiantes que la palabra, así como en la gradación de las expresiones de la belleza, el sonido tiene más variantes que el color. Como la belleza es la conformidad del espíritu con todo lo indescifrable, lo exquisito, lo inmedible y lo vago, lo bello se expresa mejor en tanto que tiene más extensión en que expresarse, menos trabas para producirse, más medios con que reflejar la abstracta necesidad, la mórbida concepción, las combinaciones tempestuosas o apacibles de esta presunción de lo venidero, religión de la soledad, propio hogar del hombre, que llamamos caprichosa fantasia. (50:59)

Esta párrafo revela hasta qué punto Marti había bebido en las fuentes simbolistas francesas, porque en él se patentiza el principio verleniano de la vaguedad y de la musicalidad. El ascendiente de los experimentos sinestésicos de Rimbaud indudablemente orientaron las siguientes líneas de Martí; escritas en I88r:

30 Ricardo Gullón, Conversaciones con Juan Ramón Jiménez (Madrid: Tau. rus, 1958), pp. 58-59.

31 En el prólogo a Cantos de vida y esperanza (1905) afirmó: "El movimien. to de libertad que me tocó iniciar..." 
Entre los colores y los sonidos hay una gran relación. El cornetín de pistón produce sonidos amarillos; la flauta suele tener sonidos azules y anaranjados; el fagot y el violín dan sonidos de color de castaña y azul de Prusia, y el silencio, que es la ausencia de los sonidos, el color negro. El blanco lo produce el oboe: 32

A más de la influencia simbolista, la teoría martiana evidencia la huella del arte glíptico de los seguidores de Gautier, como el texto que a continuación of recemos (pubicado en $\mathrm{r} 88 \mathrm{I}$ en la segunda entrega de la Revista Venezolana) comprobará:

Sólo que aumentan las verdades con los días, y es fuerza que se abra paso esta verdad acerca del estilo: el escritor ha de pintar, como el pintor. No hay razón para que el uno use de diversos colores, y no el otro. $(20: 32)$

La necesidad de cultivar un estilo coloreado y plástico, concepto en consoniancia no sólo con el arte parnasiano sino con el de los impresionistas, reaparece en unas notas escritas entre I886 y 1887 :

El estilo tiene su plasticidad, y después de producirlo como poeta, se le debe juzgar y retocar como pintor: componer las distancias y valores, agrupar con concierto, concentrar los colores esenciales, desvanecer los que dañan la energía central. (63:175)

En $r 887$ Martí declaró a su íntimo amigo Manuel A. Mercado que buscaba anhelosamente formas cromáticas de expresión:

¿Y yo que a veces estoy, con toda mi abundancia, dando media hora vueltas a la pluma, y haciendo dibujos y puntos alrededor del vocablo que no viene, como atrayéndolo con conjuros y hechicerías, hasta que al fin surge la palabra coloreada y precisa. $(68: 174-175)$

En otros escritos se funden los elementos parnasianos y simbolistas con el principio clásico de la proporción y armonía. Estos que siguen provienen de apuntes y fragmentos sin fecha:

Hay algo de plástico en el lenguaje, y tiene él su cuerpo visible, sus líneas de hermosura, su perspectivas, sus luces y sombras, su forma escultórica y su color, que sólo se perciben viendo en él mucho, revolviéndolo, pesándolo, acariciándolo, puliéndolo. En todo gran escritor hay un gran pintor, un gran escultor y un gran músico. (73:87)

32 José Martí, Sección constante, ed. Pedro Grases (Caracas: Imprenta Nacional, 1955), p. 126. 
Para mí las palabras han de tener a la vez, en saludable [proporción], sin exceso de ninguna de las tres, sentido, música y color. (73:132)

Esta es la gran ley estética, la ley matriz y esencial. Ni el lenguaje ha de salirse, por lo sobrentusiasta o lo frío, del tono natural del sentimiento, ni los colores han de ser más que lo que requiere la importancia del tema... $(73: 45)$

En r889, en la Edad de oro alude a su deseo de hacer poesía ". .de manera que se vea en los versos como si estuviera pintando con colores" $(24: 27)$, y en el mismo año habla de "frases de colores" al poner de manifiesto su creencia en la efectividad de la literatura como magisterio social:

... una cosa es echar al aire frases de colores para que se las lleve el viento como las bombas de jabón, y otra clavar en los corazones de los hombres, como el asta banderas en la cuja, las ideas con que se han de levantar los pue. blos. (38:9)

Los textos citados, casi todos anteriores a r888, son de genuina prosapia modernista, y a base de ellos, y de lo dicho en las secciones precedentes de este trabajo, tendremos que disentir con críticos como el profesor Allen W. Phillips, quien en su excelente estudio sobre "Rubén Darío y sus juicios sobre el modernismo", le concede al vate nicaragüense la gloria de haber iniciado el arte modernista. ${ }^{3:}$

La primera exposición teórica de estirpe netamente modernista en la obra de Rubén data de I888, y su estilo delata la presencia de Martí (tener luz y color, bablar como las águilas callan, la trampa de plata etc.) cuya prosa comienza a fecundizar la de Darío a partir de 1886 . Escribe Darío:

Creen y aseguran algunos que es extralimitar la poesía y la prosa, llevar el arte de la palabra al terreno de otras artes, de la pintura verbigracia, de la escultura, de la música. No. Es dar toda la soberanía que merece al pensa. miento escrito, es hacer del don humano por excelencia un medio refinado de expresión, es utilizar todas las sonoridades de la lengua en exponer todas las claridades del espíritu que concibe... Janín llamaba "estilo en delirio". al estilo de Julio y Edmundo, y consideraban un absurdo, una locura, pretender pintar el color de un sonido, el perfume de un astro, algo como aprisionar el alma de las cosas ... Ah, y esos desbordamientos de oro, esas

33 Revista Iberoamericana, XXIV (1959), p. 42 y 49. 
frases kaleidoscópicas, esas combinaciones de palabras armónicas, en períodos rítmicos, ese abarcar un pensamiento en engastes luminosos, todo eso es sencillamente admirable... Juntar la grandeza o los esplendores de una idea en el cerco burilado de una buena combinación de letras; lograr no escribir como los papagayos hablan, sino hablar como las águilas callan; tener luz y color en un engarce, aprisionar el secreto de la música en la trampa de plata de la retórica, hacer rosas artificiales que huelen a prima. vera, he ahí el misterio. ${ }^{34}$

En este artículo titulado "Catulo Méndez [sic.], Parnasianos y Decadentes" hay resonancias no sólo de giros martianos sino de conceptos doctrinales relacionados con el arte literario, y en particular, con el cromatismo modernista, que Martí - como ya hemos comprobado- habia desarrollado muchos años antes. Está fuera de nuestro propósito seguir comparando las ideas teóricas de Martí y Dario; baste decir que en los años posteriores a 1888 hay inequívocas coincidencias, tanto en la teoría de la cronología como en todos los aspectos de la expresión modernista. $Y$, en varios casos, no sería aventurado hablar no ya de coincidencias sino de influencias, puesto que la preceptiva martiana alcanzó su desenvolvimiento máximo antes que la de Darío. Sirva para comprobar esta ase. veración el siguiente rosario de textos martianos escritos todos antes de la primera exposición teórica rubeniana de filiación modernista:

[1875]

La música es más bella que la poesía porque las notas son menos limitadas que las rimas: la nota tiene el sonido, y el eco grave, y el eco lánguido con que se pierde en el espacio: el verso es uno, es seco, es solo: - alma comprimida- forma implacable - ritmo tenacísimo.

La poesía es lo vago; es más bello lo que de ella se aspira que lo que es en sí. (50:23-24)

\section{[1881]}

... el escritor ha de pintar, como el pintor. No hay razón para que el uno use de diversos colores, y no el otro. Con las zonas se cambia de atmósfera, y con los asuntos de lenguaje. Que la sencillez sea condición recomendable, no quiere decir que se excluya del traje un elegante adorno. (20:32-33)

\section{[1882]}

El verso es perla. No han de ser los versos como la rosa centifolia, toda llena de hojas, sino como el jazmín del Malabar, muy cargado de esencias La hoja ha de ser nítida, perfumada, sólida, tersa. Cada vasillo suyo ha de ser un vaso de aromas. El verso, por donde quiera que se quiebre, ha de dat

34 Obras desconocidas de Rubén Dario, pp, 168-170. 
luz y perfume... Pulir es bueno, más dentro de la mente y antes de sacat el verso al labio. El verso hierve en la mente, como en la cuba el mosto. Mas ni el vino mejora, luego de hecho, por añadirle alcoholes y taninos; ni se aquilata el verso, luego de nacido, por engalanado con aditamentos y aderezos: $(20: 66-67)$

[1887]

El arte de escribir ¿no es reducir? La verba mata sin duda la elocuencia.

Hay tanto que decir, que ha de decirse en el menor número de palabras posibles: eso sí, que cada palabra lleve ala y color. (34:45)

[1887]

No hay música más difícil que la de una buena prosa. (68:159)

Podríamos continuar con citas de Martí, pero los textos que ya hemos reproducido demuestran a las claras que Martí se anticipó a Dario en el empleo del azul, en la elaboración de una teoría cromática con raíces parnasianas y simbolistas, y, en la formación de una teoría literaria ciento por ciento modernista. De este iniciador del modernismo hay que decir, con Pedro Henríquez Ureña, que "en el terreno del estilo, así como en lo que está detrás del estilo y se hace expresión su poder de invención fue inagotable." ${ }_{3 \pi}$

IVAN A. SCHULMAN

Washington University,

St. Louis, Missouri.

35 Las corrientes literarias en la América bispánica (México: Fondo de Cultura Económica, 1954), p. 168. 
